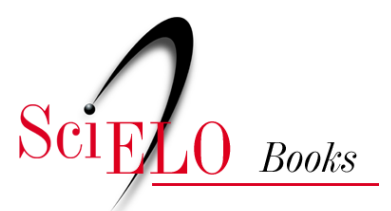

\title{
2. Regionalização e coordenação intergovernamental
}

\author{
Patrícia Ribeiro \\ Elizabeth Barros
}

\section{SciELO Books / SciELO Livros / SciELO Libros}

RIBEIRO, P., and BARROS, E. Regionalização e coordenação intergovernamental. In: UGÁ, M.A.D., et al., (orgs.). A gestão do SUS no âmbito estadual: o caso do Rio de Janeiro [online]. Rio de Janeiro: Editora FIOCRUZ, 2010, pp. 59-68. ISBN: 978-85-7541-592-4. Available from: doi: 10.7476/9788575415924.0004. Also available in ePUB from: http://books.scielo.org/id/c2hxb/epub/uga-9788575415924.epub.

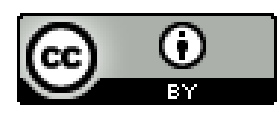

All the contents of this work, except where otherwise noted, is licensed under a Creative Commons Attribution $\underline{4.0 \text { International license. }}$

Todo o conteúdo deste trabalho, exceto quando houver ressalva, é publicado sob a licença Creative Commons Atribição 4.0. 


\title{
Regionalização e Coordenação INTERGOVERNAMENTAL'
}

Patrícia Ribeiro Elizabeth Barros

\begin{abstract}
Assegurar o direito à saúde aos cidadãos e prover, com qualidade, uma atenção oportuna, continuada e adequada, constituem questões que vêm gerando desafios ao Sistema Único de Saúde (SUS) desde sua criação. Há razoável consenso de que isso só será possível com a constituição de redes de serviços regionalmente articuladas. Mas regionalizar a oferta de serviços de saúde é tarefa complexa, particularmente no contexto federativo brasileiro, caracterizado por inúmeras atribuições compartilhadas entre os entes governamentais e por grande diversidade de condições sociais, econômicas e culturais entre as unidades federadas.

Nesta federação de desiguais, estabelecer as condições de operação de um sistema de saúde nacional, regido por princípios gerais, mas capaz de respeitar as necessidades particulares de cada lugar, exige elevada capacidade de articulação e desenhos institucionais flexíveis.

A formulação de políticas públicas no Brasil, em todas as áreas, tem sido pouco capaz de valorizar as especificidades das diferentes regiões e localidades. Milton Santos chamou a atenção, seguidas vezes, para o processo de desterritorialização das políticas públicas brasileiras, apontando

o desinteresse pela noção de território na produção da política. Interpreta-se o país como se ele fosse uma planta vivendo sem raízes, o espaço nacional sendo considerado apenas como um receptáculo, uma forma passivamente adaptável aos movimentos da sociedade. (Santos, 2000)

Essa limitação apontada por Santos tem conduzido á formulação de estratégias que propõem soluções padronizadas, como se fosse possível contemplar as necessidades da população ribeirinha da Amazônia e as da residente na área metropolitana de São Paulo ou

\footnotetext{
1 Este artigo tem como referência trabalho apresentado em 2005, em parceria com Gilson Cantarino, no I Encontro de Gestores Estaduais, Provinciais e Departamentais de Sistemas Sul-Americanos de Saúde, promovido pelo Conselho Nacional de Secretários de Saúde (Conass) e pela Organização Pan-Americana da Saúde (Opas), com o apoio dessa organização e do Ministério da Saúde.
} 
do Rio de Janeiro num desenho único e uniforme de política, ignorando a especificidade das relações sociais produtoras do espaço.

$\mathrm{Na}$ área da saúde, essa impropriedade começa a ser enfrentada sob a forma de planos regionais diferenciados e de mecanismos de programação e partilha de recursos específicos para algumas situações regionais.

Além disso, a nova perspectiva de articulação intergovernamental estabelecida no Pacto pela Saúde favorece a visão das regiões em suas particularidades. Mas há muito que avançar para alcançar formas organizacionais e modelos de gestão capazes de promover o acesso e a qualidade da atenção, adequados a distintas realidades. Estes precisam ser construídos não apenas como resultado de racionalidade técnica, mas como parte de processo social de aproximação entre a gestão e os diferentes atores setoriais - gestores, usuários, trabalhadores, administradores e todas as forças sociais, econômicas e políticas interessadas.

\section{A Região como Espaço de Coordenação Intergovernamental e de Cooperação Horizontal em Sistemas Federativos}

A regionalização como proposta política está relacionada à tendência à redivisão territorial do poder, engendrada pelos processos simultâneos de globalização da economia mundial, desconcentração espacial da atividade produtiva e descentralização político-administrativa que atravessaram os Estados Nacionais na década de 1990. Aparece como resposta à concentração do poder de decisão em escala nacional e global; aos desafios colocados por estes processos à reorganização federativa do poder dos Estados; à má distribuição dos frutos do desenvolvimento tecnológico; às graves desigualdades que se estabeleceram na dinâmica econômica inter e intrarregional (Fiori, 1995; Affonso, 1995).

Em contexto de mundialização de redes e das relações econômicas e sociais e de riscos relativos ao descontrole da moeda, à segurança pública, ao mercado financeiro e aos crescentes déficits comerciais e fiscais, a regionalização surge como tendência acentuada no cenário internacional. No plano nacional, a simultânea transferência de funções para níveis subnacionais, ampliando riscos de decomposição e fragmentação dos governos centrais (Camargo, 2001), coloca em pauta a regionalização como estratégia articuladora, como possibilidade de conciliar unidade e diversidade, cooperação e competição, integração e descentralização/autonomia.

Nos sistemas federativos, a questão da regionalização está associada ao debate sobre limites e possibilidades do princípio de subsidiariedade $;^{2}$ funções de cooperação vertical e horizontal e interdependência dos entes; realidades de grande diversidade e heterogeneidade econômica, política e territorial. Na República Federal da Alemanha, optou-se por

\footnotetext{
2 O princípio da subsidiariedade, segundo Camargo (2001: 85-86), promove políticas diretamente conduzidas pela autoridade ou instituição mais próxima do cidadão: "Esse princípio estabelece, no plano das iniciativas, a prioridade da sociedade sobre o Estado, e dentro do setor público, a primazia do município sobre o estado e deste sobre o governo federal. Apenas em caso de omissão ou carência, a instância superior assume iniciativas que podem ser conduzidas pela instância inferior".
} 
uma perspectiva microrregional e pela adoção de mecanismos de cooperação financeira horizontal entre estados no planejamento governamental.

Essa conjuntura complexa se reflete nos processos nacionais de descentralização política do setor saúde e revaloriza as relações intergovernamentais no estabelecimento de novas formas de coordenação sanitária face ao fortalecimento da gestão local. $\mathrm{Na}$ Espanha, onde, no processo de descentralização do sistema nacional de saúde, o governo central de fato transferiu responsabilidades fiscais, políticas e administrativas aos governos regionais e locais para a realização de uma gestão efetiva do sistema em novas bases, esse debate está presente. Em artigo recente, López-Casanovas e Rico (2003) destacam como tarefa subsequente a essa primeira etapa a de se estabelecer uma nova coordenação sanitária naquele país, adequada ao novo contexto de descentralização, em que o governo central atue como facilitador das iniciativas das comunidades autônomas, promovendo a cooperação horizontal entre elas e reorientando a competição para a obtenção de melhorias de eficiência.

No Brasil, a enorme heterogeneidade regional, no que se refere à desigual capacidade econômica e às conhecidas assimetrias sociais, foi agravada por sucessivas crises econômicas, que perpetuaram um nível extremamente elevado de disparidades inter-regionais e intrarregionais. As dificuldades que se acumulam no financiamento público de um processo de descentralização política descoordenado, conflitivo e ainda não consolidado, reforçam a coordenação regional e a cooperação intergovernamental como mecanismos de soldagem da nossa federação.

Mas promover um processo de regionalização eficaz transcende a articulação intergovernamental. Regiões não são meros recortes arbitrários do território, e o próprio processo de globalização produziu uma releitura do espaço local. Santos (2006: 184), ao analisar as mudanças representadas pela globalização, destaca a proeminência das redes mundiais e suas repercussões espaciais, mas ressalta também que "é a sociedade nacional, através dos mecanismos de poder, que distribui, no país, os conteúdos técnicos e funcionais, deixando os lugares envelhecer ou tornando possível sua modernização”. Ressalva, contudo, que "as decisões nacionais interferem sobre os níveis inferiores da sociedade territorial por intermédio da configuração geográfica, vista como um conjunto. Mas somente em cada lugar ganham real significação" (Santos, 2006: 184). Segundo o autor, é no lugar que "fragmentos da rede [mundial] ganham uma dimensão única e socialmente concreta, graças a ocorrência, na contiguidade, de fenômenos sociais agregados, baseados num acontecer solidário, que é fruto da diversidade, e num acontecer repetitivo, que não exclui a surpresa" (Santos, 2006: 182).

Admitida essa complexidade, regionalizar pressupõe o respeito aos processos e às interações sociais locais, e a colocação das necessidades da população no centro da discussão, sendo os lugares articulados por meio da ação regulatória da União e dos estados. Isso significa aceitar que, num processo de regionalização do sistema de saúde, que é universal e nacional, os recortes territoriais ganhem nova dimensão e as fronteiras tornem-se difusas, o que potencializa possibilidades de conflitos. A negociação torna-se, 
assim, imprescindível na concretização dos pactos políticos necessários à identificação de alternativas para os dilemas do sistema de saúde e compatíveis com o cenário de fortalecimento do federalismo brasileiro.

\section{Federalismo, Relações Intergovernamentais e Sistema de Saúde}

Localizar o processo de descentralização/regionalização do cuidado à saúde no espaço das relações políticas federativas constitutivas do Estado brasileiro, por sua forte determinação na efetividade dos resultados das políticas públicas neste campo de ação governamental, é condição para encontrar saídas para os dilemas setoriais.

A aproximação aos temas do federalismo e, em particular, das relações intergovernamentais não é fácil. A literatura nacional, pródiga em estudos que abordam o federalismo fiscal a partir de análises econômicas, conta, porém, com uma produção científica relativamente restrita de trabalhos que privilegiam a questão federativa nacional em seus aspectos político-institucionais, particularmente no que tange a estudos que analisem com profundidade o modus operandi governamental na gestão pública das áreas sociais, com enfoque nas relações entre União, estados e municípios. ${ }^{3}$

Há que se considerar, contudo, que a questão da divisão territorial do poder, como objeto de estudo sistemático da ciência política, só muito recentemente foi revalorizada, como consequência dos complexos problemas empíricos colocados pelas novas dinâmicas territoriais, como a descentralização do poder no plano nacional, de alcance quase global, o estabelecimento de laços regionais ou confederativos entre as nações (União Europeia) e a tentativa de manutenção da integridade espacial de países grandes e/ou com enorme heterogeneidade socioeconômica, cultural e política (Abrucio, 2001).

Assim, tanto o estudioso que busca compreender melhor as especificidades das experiências nacionais de descentralização quanto o gestor governamental que atua como protagonista nas relações intergovernamentais para a definição de estratégias de regionalização se veem diante da tarefa de desembaraçar ao menos parte da intricada trama de interações econômicas, sociais e culturais que atravessa a dimensão político-institucional nos espaços de gestão pública.

Não é nossa pretensão aqui assumir compromisso de tal envergadura. No entanto, a partir da revisão bibliográfica realizada e da experiência acumulada na análise da gestão do SUS, encontramos a possibilidade de sistematizar algumas questões que, a nosso ver, poderão contribuir para o debate sobre o estabelecimento de uma melhor coordenação intergovernamental do processo de regionalização do cuidado à saúde e de políticas institucionais orientadas a uma maior equidade social e integração política. ${ }^{4}$

\footnotetext{
3 Dentre os autores com publicações que constituem referência obrigatória sobre o tema, podemos citar Celina Souza, Celso Daniel, Eduardo Kugelmas, Fernando Luiz Abrucio, Fernando Rezende, José Luis Fiori, José Roberto Afonso, Marta Arretche, Maria Hermínia Tavares de Almeida, Pedro Luiz Barros Silva, Rui de Britto Affonso, Sulamis Dain e Thereza Lobo.

4 Importante destacar na bibliografia consultada, pela influência que tiveram na construção deste breve ensaio, os estudos de Moraes (2001); Schultze (2001); e Spahn (2001), que analisam as relações intergovernamentais na República Federal da Alemanha, e o estudo de López-Casanovas e Rico (2003), que analisa a experiência espanhola de descentralização sanitária.
} 
A primeira dessas questões refere-se à necessidade de se 'ancorar o processo de regionalização da atenção à saúde no contexto das relações federativas do Estado brasileiro'. Para que se criem reais condições e oportunidades de implementação de um novo modo de gestão regional, é imprescindível incorporar à formulação de políticas de regionalização sanitária o exame criterioso das implicações que as mudanças introduzidas pela reorganização do cuidado à saúde nos diversos recortes regionais trazem para as relações financeiras e para o arranjo político-institucional da gestão intra e intergovernamental setorial.

No que diz respeito às 'relações financeiras', tal perspectiva impõe avaliar:

- a estrutura de financiamento da ação setorial no arranjo federativo nacional; ${ }^{5}$

- a necessidade de rever a divisão de funções e gastos entre os diferentes níveis de governo e unidades federadas;

- a capacidade de cada ente envolvido participar com recursos próprios no financiamento das mudanças;

- a pertinência e viabilidade de se instituir mecanismos de equalização financeira intra e/ou inter-regional;

- as necessidades e possibilidades de endividamento público;

- a possibilidade/adequação de constituir e conferir maior autonomia a instancias regionais para gestão e execução financeira.

Poder-se-ia, dessa forma, alcançar maior clareza quanto à configuração mais eficiente e eficaz da divisão de autoridades, responsabilidades e competências.

No que se refere à 'estrutura político-institucional', supõe analisar:

- a extensão/adequação do marco legal que regula a ação regionalizada da federação brasileira quanto ao planejamento regional, aos investimentos em infraestrutura e ao acompanhamento e avaliação; ${ }^{6}$

- as formas cooperativas de interação governamental (verticais e horizontais) em operação (ou passíveis de incorporação);

\footnotetext{
5 Esta tarefa remete necessariamente ao acompanhamento sistemático do processo em curso de regulamentação complementar e operacionalização da Emenda Constitucional n. 29 (EC29), promulgada em de 13 de setembro de 2000, que, entre outras matérias, aborda critérios básicos para a conceituação de "ações e serviços públicos de saúde”; despesas que integram e não integram este conjunto; base vinculável do montante de recursos financeiros a serem aplicados por cada esfera de governo; formas de acompanhamento, fiscalização e controle do cumprimento das disposições constitucionais (Brasil, 2002).

6 A Constituição Brasileira e a legislação complementar contêm dispositivos para a regulação de iniciativas de cooperação entre a União, os estados e os municípios, orientadas ao equilíbrio do desenvolvimento e ao bem-estar, no âmbito nacional, e à redução de desigualdades regionais. Estabelece também a prerrogativa dos estados instituírem regiões metropolitanas, aglomerações urbanas e microrregiões, mediante lei complementar, para a organização, o planejamento e a execução de funções públicas de interesse comum. Além disso, há que verificar interfaces entre os dispositivos da Lei da Reforma Urbana e os processos setoriais.

7 Este esforço deve contemplar a análise das experiências de 'consorciamento' intermunicipal, que, na saúde, tiveram uma grande disseminação nos anos 90 e ainda hoje são objeto de polêmica no debate setorial e na literatura sobre federalismo e a análise da interação intergovernamental nas regiões metropolitanas, muito polarizadas politicamente, que até recentemente eram de responsabilidade dos governos estaduais, e que, segundo vários autores (Camargo, 2001; Daniel, 2001; Abrucio; 2001), foram abandonadas por estas esferas.
} 
- as arenas administrativas e de planejamento intergovernamental e/ou regional já estabelecidas (ou cuja necessidade está identificada);

- a possibilidade de mecanismos regionais de participação social para ampliar a governança, conferindo maior legitimidade às políticas regionais.

Tais análises possibilitariam uma interação produtiva e renovadora com a estrutura institucional existente para a formulação de proposições que busquem conferir uma maior racionalidade à implementação das políticas setoriais e que promovam uma integração possível com outras políticas regionais. Além disso, contextualizariam o desenho de propostas destinadas a potencializar articulações intersetoriais, intra e intergovernamentais, necessárias à condução de políticas voltadas para o alcance de maior equilíbrio intra e inter-regional. ${ }^{8}$

Esta ancoragem da regionalização setorial na organização federativa do Estado brasileiro poderia contribuir não apenas para a melhor coordenação intra e intergovernamental dos processos políticos e dos esforços institucionais necessários, mas principalmente para a consolidação de relações de cooperação entre União, estados e municípios, nos territórios regionais, fundadas em múltiplas e complementares parcerias.

Uma segunda questão que merece atenção quanto ao objetivo de assegurar efetividade às iniciativas intergovernamentais de gestão do espaço regional é a 'qualidade democrática do arranjo político-institucional' a estabelecer, relacionada à base de legitimidade da ação governamental e à definição de formas e mecanismos de mobilização e participação social para a gestão e o controle público dos atos governantes. Esta questão, bastante complexa pelo conteúdo político e ideológico que concentra, requer um tratamento muito cuidadoso quando referida a experiências concretas de coordenação intergovernamental de políticas públicas. ${ }^{9}$ No entanto, com a devida cautela, e dado o fato de que a ampla e diversa participação social alcançada na dinâmica político-institucional do SUS já vem pautando este tema, vale registrar algumas reflexões.

A amplitude da base de legitimidade da ação governamental e a sustentabilidade da política pública dependem da maior ou menor interlocução que os projetos governamentais estabeleçam com atores sociais e políticos locais, sujeitos relevantes da produção e sustentação dos eventos (ideias ou fatos) relacionados às mudanças. Aqui, vale lembrar uma vez mais Milton Santos (2006) quando se refere à importância do lugar como espaço de existência e coexistência, expressão do mundo vivido onde relações de ordem objetiva se articulam com relações subjetivas, relações verticais derivadas do poder hegemônico se imbricam com relações horizontais de coexistência e resistência e se define a escala das forças operantes, determinada pela força do emissor dos eventos.

\footnotetext{
8 Uma interessante experiência de construção de um modelo de gestão regional (Grande ABC paulista), que oferece referências significativas para o estudo das relações federativas no Brasil neste âmbito, especialmente no que se refere à gestão de grandes conglomerados urbanos, é apresentada no artigo "Autonomia municipal e as relações com os estados e municípios” de Celso Daniel (Daniel, 2001).

9 Uma boa síntese do debate acadêmico relativo ao tema pode ser encontrada em Carneiro (2004). Disponível em: <www.eg.fjp.mg.gov.br/index.php?option=com_content\&task=view\& $i d=576 \&$ Itemid=181>.
} 
Sendo assim, é importante contemplar, nos processos de formulação e implementação de políticas de regionalização do cuidado à saúde, para além da participação dos atores governamentais dos três níveis político-administrativos da federação e dos atores sociais representados nos conselhos de saúde, formas e mecanismos de inclusão/incorporação de outros atores ao processo decisório setorial. Isto implica a identificação de processos intervenientes e de segmentos relevantes da sociedade civil que não participam dos fóruns institucionalizados de participação social do SUS, de grupos cuja inserção na gestão do sistema de saúde e na execução dos serviços é crucial para as mudanças necessárias no plano gerencial e assistencial, e, especialmente, de atores que possam vocalizar as demandas dos usuários do sistema que sofrem com a peregrinação territorial em busca da resolução de seus problemas.

Quanto à participação social na gestão e no controle público da ação governamental, esta se situa no campo de proposições - e de práticas sociais - do que vem sendo chamado de 'responsabilização societária' ou 'responsabilização social', tanto na literatura que analisa o federalismo como na literatura que analisa o tema da governança. No centro dessas análises, estão os conceitos de enforcement e accountability, amplamente disseminados no debate público sobre a gestão governamental, e que se referem à obrigação dos governantes de cumprir a lei e de informar, explicar e prestar contas de suas decisões políticas, administrativas, profissionais, financeiras, morais, legais, constitucionais, visando ao exercício transparente do poder e à sua sujeição a sanções (Carneiro, 2004). Também se incluem aqui as iniciativas destinadas a compartilhar poder de decisão, como as representadas por conselhos gestores. A qualidade democrática da atuação governamental resultaria da combinação de diversos mecanismos e estratégias institucionais e societais de responsabilização que articulassem ações do Executivo, Legislativo, Judiciário e do cidadão, visando a assegurar o acesso e garantir o direito à saúde.

Sob a perspectiva de que no cerne destas preocupações estejam a questão da republicanização do espaço da política e a efetivação das diretrizes democráticas de soberania popular, seria interessante que, já no momento de formulação das políticas de regionalização sanitária, se buscasse, a partir de colaboração entre os três Poderes e o Ministério Público, identificar estratégias para a responsabilização dos governos e dos diferentes atores sociais no cumprimento da agenda política da regionalização e - por que não? - na implementação de políticas incentivadoras de parceria e cooperação.

A maior aproximação entre poder público e sociedade, a nosso ver, além de promover maior interação das instituições informais da sociedade com as regras formais para a organização de seus interesses no processo decisório governamental, ampliando tanto a legitimidade das proposições e inovações quanto a cooperação interinstitucional neste ambiente político, provavelmente traria para o cenário setorial alternativas de solução ainda não tentadas e uma maior chance de eficácia social para suas políticas.

A terceira e última questão que sinalizamos para o debate setorial diz respeito à importância da 'transparência, da articulação interinstitucional e da cooperação administrativa no planejamento dos recursos financeiros para o financiamento e a gestão do processo de regionalização', aspectos apresentados como condições essenciais para a eficácia das 
políticas institucionais na literatura que analisa as relações financeiras intergovernamentais em experiências federativas.

Conhecimento sobre a realidade que se pretende modificar; clareza de propósitos na formulação e implementação de políticas de curto, médio e longo prazos; gestão orçamentária coordenada e monitorada; planejamento compartilhado e sensível às necessidades de mudanças institucionais; prescrições administrativas gerais para garantir a interação entre as instâncias de governo; compromisso com a qualidade do gasto; compromisso com a eficiência e a eficácia das intervenções públicas (critérios de eficiência e desempenho); processo de tomada de decisão direcionado à obtenção de consensos; justiça e racionalidade na repartição dos recursos públicos; mecanismos claros de compensação financeira intergovernamental; e criação de formas estáveis de accountability financeira, compõem o quadro de desafios para que a coordenação intergovernamental, no espaço em que se implementam as políticas, possa estabelecer a necessária cooperação vertical e horizontal entre os entes governamentais para uma gestão solidária dos recursos públicos na reorganização do cuidado à saúde da população.

Isto supõe a revitalização e o aperfeiçoamento da estrutura político-institucional de gestão do SUS (mecanismos de cooperação intergovernamental existentes; sistemas de interação entre as diversas áreas de atuação setorial; arenas de negociação instituídas; estrutura e lógica de financiamento da gestão descentralizada); a qualificação do processo decisório e da administração financeira; e a criação de espaços de ação intra e intergovernamental no planejamento orçamentário de políticas regionais.

A nosso ver, este é o campo de redirecionamento político mais difícil porque implica reacomodação de interesses e redistribuição do poder político, institucional e financeiro estabelecido; equilíbrio na competição entre as unidades político-administrativas pela ampliação de seus orçamentos respectivos e pela ampliação de sua rede de serviços; mudança na lógica centralizadora e fragmentadora da gestão governamental; integração intergovernamental para uma alocação dos recursos financeiros setoriais orientada à equidade intra e inter-regional; definições claras quanto às responsabilidades regulatórias e executivas de cada nível de governo; maior clareza quanto à divisão das competências administrativas; alta capacidade técnica da burocracia governamental.

Diante da complexidade e simultaneidade de relações intergovernamentais horizontais e verticais que um planejamento eficaz dos recursos financeiros demanda no contexto da regionalização setorial, tudo leva a crer que o êxito da coordenação intergovernamental desse processo depende da capacidade dos atores setoriais incluírem este objetivo como prioridade política na agenda de governo de cada ente federativo.

\section{Considerações Finals}

No desenho de políticas públicas, a questão federativa assume particular complexidade na especificidade representada pelo caso brasileiro, em que entre as unidades federadas incluem-se estados e municípios, todos dotados de autonomia de gestão. Nesse contexto, 
não é de estranhar que a implementação de um sistema nacional de saúde simultaneamente descentralizado e integrado, encontre tamanhas dificuldades para avançar. Esse fator aliado ao fato de que nossa cultura política é patrimonialista e competitiva representa permanente desafio à criatividade e à capacidade de negociação de todos os gestores comprometidos com o aperfeiçoamento do SUS.

Há crescente consciência de que apenas com a composição de redes regionalizadas se conseguirá assegurar organicidade ao sistema, superando a fragmentação e a ausência de articulação entre unidades federadas, níveis de atenção e unidades de provisão de serviços, de modo a garantir, ao conjunto da população, o acesso às ações e aos serviços necessários ao atendimento integral de suas necessidades.

A inviabilidade técnica e econômica de se assegurar em cada município e mesmo em cada estado - no espaço circunscrito por suas fronteiras jurisdicionais - serviços de todos os níveis de complexidade, compatíveis com o dever do Estado, previsto na Constituição Brasileira de prover assistência integral e universal à população, e a necessidade de que a articulação no interior da rede respeite processos e inter-relações sociais e econômicas historicamente estabelecidas nos diferentes territórios, demandam esforços de negociação e compromissos de caráter duradouro, que transcendam interesses particulares de cada governante e confiram ao sistema nacional de saúde a sustentabilidade necessária para que se cumpra sua missão de garantir, no que lhe cabe, o direito à saúde. Isto significa conferir às relações sociais papel de relevância na dinâmica setorial, equilibrando com isso dinâmicas políticas particulares e interesses sociais.

Esse é o desafio maior, porque incide sobre interesses diferenciados, muitas vezes divergentes. A consolidação de redes regionais pressupõe um novo entendimento de hierarquias e verticalidades, a partir da disseminação do poder de decidir para diferentes instâncias e lugares. Há que haver, em relação a muitas questões, ampliação do poder do nível local ou das unidades provedoras de serviços simultaneamente a um fortalecimento dos papéis dos níveis federal e estadual na regulação e coordenação do sistema regionalizado. E, acima de tudo, é imprescindível a construção de relações de cooperação e a aceitação de que cada parte do sistema é elo necessário ao cumprimento das suas diretrizes, para que se assegure a cada cidadão brasileiro o acesso e a integralidade da atenção, independentemente do lugar em que vive.

\section{REFERÊNCIAS}

ABRUCIO, F. L. A reconstrução das funções governamentais no federalismo brasileiro. In: HOFMEISTER, W. \& CARNEIRO, J. M. B. (Orgs.). Federalismo na Alemanha e no Brasil. São Paulo: Fundação Konrad Adenauer, 2001. v. 1. (Série Debates, n. 22)

AFFONSO, R. B. A federação no Brasil: impasses e perspectivas. In: AFFONSO, R. B. \& SILVA, P. L. B. (Orgs.). A Federação em Perspectiva: ensaios selecionados. São Paulo: Fundap, 1995.

BRASIL. Ministério da Saúde. A operacionalização da Emenda Constitucional n. 29 (2001: Brasília). Relatório do Seminário sobre a Operacionalização da Emenda Constitucional n. 29, Brasília, 19, 20 e 21 set. 2001. Relatório. Brasília: Ministério da Saúde, Subsecretaria de Assuntos Administrativos, 2002. 
CAMARGO, A. Federalismo e o princípio da subsidiariedade: notas sobre a experiência recente do Brasil e da Alemanha. In: HOFMEISTER, W. \& CARNEIRO, J. M. B. (Orgs.). Federalismo na Alemanha e no Brasil. São Paulo: Fundação Konrad Adenauer, 2001. v. 1. (Série Debates, n. 22)

CARNEIRO, C. B. L. Governança e Accountability: algumas notas introdutórias. Belo Horizonte: Escola de Governo da Fundação João Pinheiro, 2004. (Texto para Discussão, n. 13)

DANIEL, C. Autonomia municipal e as relações com os estados e a União. In: HOFMEISTER, W. \& CARNEIRO, J. M. B. (Orgs.). Federalismo na Alemanha e no Brasil. São Paulo: Fundação Konrad Adenauer, 2001. v. 1. (Série Debates, n. 22)

FIORI, J. L. O federalismo diante do desafio da globalização. In: AFFONSO, R. B. \& SILVA, P. L. B. (Orgs.). A Federação em Perspectiva: ensaios selecionados. São Paulo: Fundap, 1995.

LÓPEZ-CASANOVAS, G. \& RICO, A. La descentralización, parte del problema sanitario o de su solución? Gaceta Sanitaria, 17(4): 319-26, 2003.

MORAES, M. R. As Relações Intergovernamentais na República Federal da Alemanha: uma análise econômico-institucional. São Paulo: Fundação Konrad Adenauer, 2001. (Série Pesquisas, n. 22)

SANTOS, M. Por uma nova federação. Correio Braziliense, 16 jul. 2000.

SANTOS, M. A Natureza do Espaço: técnica e tempo, razão e emoção. 4. ed. 2. reimpr. São Paulo: Editora da Universidade de São Paulo, 2006. (Coleção Milton Santos, 1)

SCHULTZE, R. O. Tendências da evolução do federalismo alemão: dez teses. In: HOFMEISTER, W. \& CARNEIRO, J. M. B. (Orgs.). Federalismo na Alemanha e no Brasil. São Paulo: Fundação Konrad Adenauer, 2001. v. 1. (Série Debates, n. 22)

SPAHN, P. B. Da controvérsia sobre a compensação financeira na Alemanha. In: HOFMEISTER, W. \& CARNEIRO, J. M. B. (Orgs.). Federalismo na Alemanha e no Brasil. São Paulo: Fundação Konrad Adenauer, 2001. v. 1. (Série Debates, n. 22)

\section{LeItURAs RecomendadAs}

ALMEIDA, M. E. T. Federalismo, democracia e governo no Brasil: idéias, hipóteses e evidências. Bib - Revista Brasileira de Informação Bibliográfica em Ciências Sociais, 51: 13-34, 2001.

SOUZA, C. Governos locais e gestão de políticas sociais universais. São Paulo em Perspectiva, 18(2): 27-41; 2004.

STEINBERGER, M. Território, ambiente e políticas públicas espaciais. In: STEINBERGER, M. (Org.). Território, Ambiente e Políticas Públicas Espaciais. Brasília: Paralelo 15, LGE, 2006. 